\title{
Profitability of investment in power distribution industry
}

\author{
Anna Gawlak \\ Czestochowa University of Technology, Institute of Power Engineering, 42-200 Częstochowa, \\ Poland
}

\begin{abstract}
Striving towards improving efficiency in the power sector puts an obligation on distribution companies to seek ways of reducing electricity loss. The highest energy loss in the distribution network is attested in electricity meters, in LV and MV lines and in MV/LV transformers. The paper analyses effectiveness of investment aimed to reduce energy loss in a distribution company. The analysis is carried out with the use of SPBP, IRR and NPV.
\end{abstract}

\section{Introduction}

Power industry provides a foundation and a driving force for all economic activities and development. Its role was first recognized during the industrial revolution and has been increasing ever since. Nowadays, no society can function without continuous energy supply. Considering this, it has to be acknowledged that the methodology for analyzing the cost of energy generation and distribution, including the influence of all variables, is of essential importance for planning the future of the power system.

The most important characteristic feature that distinguishes investment in the power sector from other branches of industry is that it is a long-lasting and complicated process. This is related to a relatively long life of the elements of the power system.

Polish distribution networks include elements which have been heavily exploited and require replacement or modernization.

Another feature typical of investment in the power industry is a relatively long period of return on invested capital. Besides, the capital expenditure and cost of investment are also relatively high. The main factors responsible for the investment in the distribution sector include [1-3]:

- condition of technological equipment,

- EU requirements concerning energy loss in transmission,

- the project of implementing smart grids.

The necessity of making for investment in the power industry is motivated mostly by the fact that the transmission and distribution networks include worn-out elements and are largely ineffective, with high loss and low reliability. The directions of development for the distribution network are as follows [4-8]:

*Corresponding author: gawlak@el.pcz.czest.pl 
- reducing energy loss in distribution transformers and networks. The necessity to use high-efficiency transformers follows from the general tendency to reduce loss occurring at the stage of energy transmission and distribution and is also stipulated by the Commission Regulation (EU) No 548/2014 of 21 May 2014 on implementing Directive 2009/125/EC of the European Parliament and of the Council with regard to small, medium and large power transformers, which sets a limit on the maximal level of idle and load loss in newly installed distribution transformers,

- modernizing and expanding the $110 \mathrm{kV}$ distribution network and networks of lower voltages with a view to the following:

$\circ$ minimizing technical and accounting loss by introducing new telemetric solutions,

$\circ$ increasing reliability by optimizing network configuration and reducing the length of overhead lines,

o expanding the network in order to offer services to a greater number of customers,

o connecting renewable energy sources, even if they are challenging to manage.

\section{Reducing energy loss by investment}

The study was carried out on the basis of data obtained from a distribution company covering 8 area units (OSD). The data concerned the amount of energy flowing through the particular voltage levels and the number of distribution devices. Losses were calculated by means of the program EUROEFEKT, as presented in Table 1.

Table 1. Energy loss in the distribution network [MWh].

\begin{tabular}{|l|c|c|c|c|c|c|c|c|}
\hline Loss & OSD1 & OSD2 & OSD3 & OSD4 & OSD5 & OSD6 & OSD7 & OSD8 \\
\hline in meters & 9863 & 10360 & 5593 & 9187 & 13532 & 15478 & 16036 & 9504 \\
\hline $\begin{array}{l}\text { load loss in LV } \\
\text { lines }\end{array}$ & 20439 & 9334 & 40244 & 23002 & 31533 & 25270 & 37812 & 11405 \\
\hline $\begin{array}{l}\text { idle in MV/LV } \\
\text { transformers }\end{array}$ & 37351 & 30142 & 16957 & 26341 & 34060 & 37269 & 50392 & 20502 \\
\hline $\begin{array}{l}\text { load loss in } \\
\text { MV/LV transf. }\end{array}$ & 8885 & 4072 & 11166 & 8202 & 7890 & 11581 & 21434 & 4095 \\
\hline $\begin{array}{l}\text { commercial/unit } \\
\text { [kWh/cons./year] }\end{array}$ & 63.27 & 94.37 & 68.14 & 62.03 & 77.94 & 139.8 & 139.8 & 72.65 \\
\hline other tech. in LV & 6974 & 4501 & 5042 & 6159 & 6711 & 6884 & 11391 & 3756 \\
\hline $\begin{array}{l}\text { load loss in MV } \\
\text { lines }\end{array}$ & 76475 & 36085 & 89495 & 101212 & 58654 & 80128 & 183451 & 30571 \\
\hline other tech. in MV & 7115 & 6731 & 5196 & 4691 & 7372 & 5822 & 6947 & 4042 \\
\hline $\begin{array}{l}\text { load loss in 110 } \\
\text { kV lines }\end{array}$ & 26529 & 31269 & 33174 & 55222 & 63486 & 35166 & 55190 & 13553 \\
\hline $\begin{array}{l}\text { in110/MV } \\
\text { transformers }\end{array}$ & 24343 & 19805 & 20290 & 26930 & 20098 & 19670 & 40810 & 11747 \\
\hline
\end{tabular}

Commercial loss constitutes from $13 \%$ to $31 \%$ of total balance loss in particular units, the mean being $91 \mathrm{kWh} /$ consumer/year. It is not a high value, especially considering the fact that it includes the system-related loss component, the exact value of which is not 
known due to lack of current data. It is estimated though that the system-related accounting loss component is about $60 \mathrm{kWh} /$ consumer/year for induction meters and about 30 $\mathrm{kWh} /$ consumer/year for static meters. Since there are about $50 \%$ of static meters in area units, the system-related accounting loss can be estimated at the level of 45 $\mathrm{kWh} /$ consumer/year. The highest level of illegal energy consumption occurs in OSD 7 . The main component of total loss, however, is load loss in MV lines, amounting to $33.81 \%$ in OSD 3 and to $17.24 \%$ in OSD 2. The MV/LV transformer loss is also high - the highest share is $17.43 \%$ of total balance loss in OSD 1 and the lowest $10.63 \%$ in OSD 3 . The latter unit is also characterized by the most advantageous ratio of idle loss to load loss, which indicates that the transformer power is selected adequately to the level of energy flow. Large load loss of energy in $110 \mathrm{kV}$ lines is attested OSD5, where it constitutes $20.67 \%$ of total balance loss. The lowest percentage of load loss in $110 \mathrm{kV}$ lines at the level of $9.20 \%$ occurs in OSD8. Load loss in LV lines range from $15.21 \%$ in OSD3 to $4.46 \%$ in OSD2, whereas loss in meters ranges from $6.45 \%$ in OSD8 to $2.11 \%$ of total balance loss in OSD3.

Electric energy loss can be reduced by taking the following actions:

- increasing cross-section area of lines,

- constructing additional MV/LV transformer stations,

- adjusting MV/LV transformer load to the amount of energy flowing through them,

- replacing induction meters by static ones,

- replacing transformers produced before 1975 by new ones.

Table 2 includes technical parameters of networks in the particular area units.

Table 2. Mean cross-section and length of the network lines.

\begin{tabular}{|c|c|c|c|c|c|c|c|}
\hline & $\begin{array}{l}\text { Length } \\
\text { of } 110 \\
\mathrm{kV} \text { lines } \\
{[\mathrm{km}]}\end{array}$ & $\begin{array}{l}\text { mean } \\
\text { cross- } \\
\text { section } \\
\text { of } 110 \\
{\left[\mathrm{~mm}^{2}\right]}\end{array}$ & $\begin{array}{l}\text { mean } \\
\text { length } \\
\text { of MV } \\
\text { lines } \\
{[\mathrm{km}]}\end{array}$ & $\begin{array}{l}\text { mean } \\
\text { cross- } \\
\text { section } \\
\text { of } \mathrm{MV} \\
{\left[\mathrm{mm}^{2}\right]}\end{array}$ & $\begin{array}{l}\text { mean } \\
\text { length of } \\
\text { LV lines } \\
{[\mathrm{m}]}\end{array}$ & $\begin{array}{l}\text { mean } \\
\text { cross- } \\
\text { section } \\
\text { of LV } \\
{\left[\mathrm{mm}^{2}\right]}\end{array}$ & $\begin{array}{l}\text { number } \\
\text { of } \\
\text { MV/LV } \\
\text { stations }\end{array}$ \\
\hline OSD1 & 1495 & 226.04 & 26.8 & 48.11 & 446.22 & 42.95 & 14679 \\
\hline OSD2 & 1045 & 241.96 & 22.87 & 49.30 & 504.49 & 42.05 & 9885 \\
\hline OSD3 & 397 & 263.81 & 16.57 & 48.82 & 437.52 & 46.97 & 3647 \\
\hline OSD4 & 1311 & 248.76 & 32.87 & 42.20 & 614.75 & 41.8 & 11866 \\
\hline OSD5 & 1789 & 213.49 & 23.73 & 47.67 & 514.59 & 46.61 & 11433 \\
\hline OSD6 & 1606 & 207.19 & 26.19 & 45.71 & 556.98 & 45.98 & 13139 \\
\hline OSD7 & 1478 & 210.50 & 25.88 & 46.67 & 527.14 & 48.82 & 17777 \\
\hline OSD8 & 1055 & 207.14 & 27.77 & 48.55 & 575.00 & 41.76 & 8985 \\
\hline
\end{tabular}

Table 3 specifies the expected loss reduction in OSDs. The values were obtained on the basis of the following assumptions:

- The cross-section of the $110 \mathrm{kV}$ line will be increased by increasing the volume of the conducting material by $120 \mathrm{~mm}^{2}$ per $1 \mathrm{~km}$ of the line. For example, $1 \mathrm{~km}$ of a line with the cross-section $120 \mathrm{~mm}^{2}$ can be replaced by $1 \mathrm{~km}$ of a line with the cross-section $240 \mathrm{~mm}^{2}$.

- The cross-section of the MV line will be increased by increasing the volume of the conducting material by $35 \mathrm{~mm}^{2}$ per $1 \mathrm{~km}$ of the line. For example, $1 \mathrm{~km}$ of a line with the cross-section $35 \mathrm{~mm}^{2}$ can be replaced by $1 \mathrm{~km}$ of a line with the cross-section $70 \mathrm{~mm}^{2}$. 
- The cross-section of the LV line will be increased by increasing the volume of the conducting material by $25 \mathrm{~mm}^{2}$ per $1 \mathrm{~km}$ of the line. For example, $1 \mathrm{~km}$ of a line with the cross-section $25 \mathrm{~mm}^{2}$ can be replaced by $1 \mathrm{~km}$ of a line with the cross-section $50 \mathrm{~mm}^{2}$.

Table 3. Mean yearly savings of final energy output obtained by increasing line cross-section.

\begin{tabular}{|c|c|c|c|c|c|c|}
\hline \multirow[b]{2}{*}{ Area unit } & \multicolumn{6}{|c|}{$\begin{array}{c}\text { Mean yearly savings of final energy output obtained by increasing line } \\
\text { cross-section }\end{array}$} \\
\hline & $\begin{array}{c}10 \mathrm{~km} \text { of } \\
110 \mathrm{kV} \\
\text { line [toe] }\end{array}$ & $\begin{array}{c}10 \% \text { of } \\
110 \mathrm{kV} \\
\text { line[toe] }\end{array}$ & $\begin{array}{c}60 \mathrm{~km} \text { of } \\
\mathrm{MV} \text { line } \\
\text { [toe] }\end{array}$ & $\begin{array}{c}10 \% \text { of } \\
\text { MV line } \\
\text { [toe] }\end{array}$ & $\begin{array}{c}60 \mathrm{~km} \\
\text { of LV } \\
\text { line[toe] }\end{array}$ & $\begin{array}{c}10 \% \text { of } \\
\mathrm{LV} \text { line } \\
\text { [toe }]\end{array}$ \\
\hline OSD1 & 8.14 & 121.67 & 15.73 & 528.22 & 3.33 & 107.85 \\
\hline OSD2 & 12.81 & 133.85 & 9.72 & 242.15 & 6.15 & 131.64 \\
\hline OSD3 & 32.82 & 130.30 & 9.95 & 194.86 & 4.82 & 360.58 \\
\hline OSD4 & 16.30 & 213.66 & 33.46 & 786.05 & 4.10 & 143.61 \\
\hline OSD5 & 17.26 & 308.74 & 21.67 & 365.47 & 5.22 & 188.59 \\
\hline OSD6 & 10.92 & 175.34 & 20.64 & 514.48 & 4.24 & 165.64 \\
\hline OSD7 & 18.39 & 271.82 & 51.54 & 1384.76 & 4.46 & 198.42 \\
\hline OSD8 & 4.65 & 49.02 & 10.01 & 205.09 & 3.02 & 79.03 \\
\hline
\end{tabular}

As it can be seen in Table 3, the greatest savings can be obtained in OSD3 - 3.82 toe per each kilometer of the $110 \mathrm{kV}$ line. The lowest savings at the level of 0.47 toe will be obtained in OSD8. In MV lines, the greatest savings can be achieved in OSD7, where by increasing the cross-section of $60 \mathrm{~km}$ of the line by $35 \mathrm{~mm}^{2} 51.54$ toe of energy can be saved, whereas OSD2 will have the lowest savings. As far as the LV network is concerned, the lowest savings will be obtained in OSD8, where the cross-section increase by $25 \mathrm{~mm}^{2}$ at $60 \mathrm{~km}$ of the line will yield additional 3.02 toe, and the greatest, equal to 6.15 toe will be obtained in OSD2.

Table 4. Mean yearly savings of final energy output - other options.

\begin{tabular}{|c|c|c|c|c|}
\hline $\begin{array}{c}\text { Area } \\
\text { unit }\end{array}$ & $\begin{array}{c}\text { Replacing } \\
\text { induction meters } \\
\text { by static meters } \\
\text { [toe] }\end{array}$ & $\begin{array}{c}\text { Increasing the } \\
\text { number of MV/LV } \\
\text { stations by 10\% } \\
\text { [toe] }\end{array}$ & $\begin{array}{c}\text { Replacing old } \\
\text { transformers } \\
\text { by new ones } \\
\text { [toe] }\end{array}$ & $\begin{array}{c}\text { Reducing the power } \\
\text { of existing } \\
\text { transformers by } \\
10 \% \text { [toe] }\end{array}$ \\
\hline OSD1 & 418.61 & 159.76 & 526.09 & 146.11 \\
\hline OSD2 & 571.31 & 72.96 & 220.90 & 151.28 \\
\hline OSD3 & 329.89 & 314.57 & 11.97 & -10.51 \\
\hline OSD4 & 268.46 & 179.78 & 156.56 & 82.24 \\
\hline OSD5 & 468.11 & 278.09 & 116.60 & 159.03 \\
\hline OSD6 & 789.96 & 197.53 & 319.74 & 116.53 \\
\hline OSD7 & 499.06 & 295.57 & 321.62 & 95.34 \\
\hline OSD8 & 477.67 & 89.15 & 167.82 & 88.62 \\
\hline
\end{tabular}

Replacing induction meters by static meters will yield the greatest savings in OSD6, where the number of induction meters is the biggest. Increasing the number of MV/LV stations by $10 \%$ will contribute to saving 315 and 296 toe in OSD3 and OSD7, respectively. If all transformers manufactured before 1975 are replaced, the greatest savings 
will be obtained in OSD1 - 526 toe and the smallest in OSD3 - 12 toe. Lowering the power of existing transformers and increasing their load by $10 \%$ will yield the savings in the final energy output of 159 toe in OSD5 and of 151 toe w OSD2. In OSD3 such a move would be unbeneficial since increase in transformer load would cause increase in energy loss. This indicates that in this unit the transformer power is selected optimally with respect to the network load.

Table 5 presents the results of energy loss reduction in the particular units, obtained by increasing the volume of the conducting material by $10 \mathrm{~km} \cdot \mathrm{mm}^{2}$ and adding one $\mathrm{MV} / \mathrm{LV}$ transformer station.

Table 5. Mean yearly energy savings obtained by increasing the volume of the conducting material in the area.

\begin{tabular}{|l|c|c|c|c|}
\hline Area unit & $\begin{array}{c}110 \mathrm{kV} \text { network } \\
\text { [toe] }\end{array}$ & $\begin{array}{c}\text { MV network } \\
\text { [toe] }\end{array}$ & $\begin{array}{c}\text { LV network } \\
\text { [toe] }\end{array}$ & $\begin{array}{c}\text { Adding one MV/LV } \\
\text { station [toe] }\end{array}$ \\
\hline OSD1 & 0.068 & 0.075 & 0.022 & 0.138 \\
\hline OSD2 & 0.107 & 0.046 & 0.041 & 0.088 \\
\hline OSD3 & 0.274 & 0.047 & 0.032 & 0.861 \\
\hline OSD4 & 0.136 & 0.159 & 0.027 & 0.150 \\
\hline OSD5 & 0.144 & 0.075 & 0.035 & 0.254 \\
\hline OSD6 & 0.091 & 0.098 & 0.028 & 0.151 \\
\hline OSD7 & 0.153 & 0.245 & 0.030 & 0.181 \\
\hline OSD8 & 0.039 & 0.048 & 0.020 & 0.100 \\
\hline
\end{tabular}

The highest mean savings per year at the level of 0.274 toe in the $110 \mathrm{kV}$ network will be obtained in OSD3, whereas in OSD7 in the MV network the amount of energy saved will be 0.245 toe. The lowest savings of 0.02 toe will be achieved in the LV network in OSD8. The effect of adding an extra MV/LV station will have the biggest impact on OSD3, contributing to saving 0.861 toe of energy. In OSD2 and OSD8 this effect will be much less conspicuous - only 0.088 toe and 0.1 toe of energy saved, respectively.

\section{Economic analysis}

An analysis of the effectiveness of the investment was carried out by means of the following methodology [9]:

Simple payback period/time (SPBP, SPBT) is the most often applied static criterion for assessing efficiency of investment. It is defined as a period required to recoup the funds spent on an investment. It is calculated from the time of launching an investment until the break-even point, i.e. when the return has paid for the invested funds.

Internal Rate of Return (IRR) is another metric for assessing profitability of investments. As a dynamic method, IRR represents a real return on investment. Based on the discounted cash flow, it takes into account changes in the value of assets in time. The interpretation of IRR is quite simple: the higher the value of IRR, the more profitable an investment will be. IRR can also be defined as a discount rate for which the Net Present Value (NPV) is equal to zero $(\mathrm{NPV}=0)$. IRR then stands for a rate for which a threshold of profitability is reached when the present value of outflowing cash is equal to inflowing cash.

NPV is the most important metric, which represents the difference between the present value of cash inflows and the present value of cash outflows. It can also be defined as 
surplus of present net profit over an alternative profit obtained from an investment the IRR of which is equal to the discount rate.

The following was assumed in the calculations:

- the cost of building $1 \mathrm{~km}$ of $110 \mathrm{kV}$ overhead line 447,000 PLN,

- the cost of building $1 \mathrm{~km}$ of MV overhead line 184,000 PLN and of $1 \mathrm{~km}$ cable line 176,000 PLN,

- the cost of building1 km of LV overhead line 103,000 PLN, of $1 \mathrm{~km} \mathrm{LV} \mathrm{cable}$ line 120,000 PLN,

- the cost of building a MV/LV station - a pole-mount 27,000 PLN, a pad-mount 136,000 PLN,

- the cost of balance loss $178 \mathrm{PLN} / \mathrm{MWh}$,

- depreciation rate $4 \%$,

- the cost of building MV and LV lines, and MV/LV stations were calculated as weighed arithmetic means, with lengths of overhead and cable lines used as weighs,

- $\quad$ increase in energy per year $1 \%$,

- time period for which the calculations were carried out 25 years,

- discount rate $3.9 \%$,

- net profit was assumed as the worth of energy loss reduction,

- the cost of replacing a single-phase meter 43 PLN, replacing a three-phase meter 56 PLN,

- the cost of a single-phase static meter 49 PLN, a three-phase static meter 105 PLN,

- depreciation rate for meters $12.5 \%$,

- time period for which the calculations were carried out in the case of meters 8 years.

The profitability assessment was carried out for the following cases:

- increasing the cross-section of the $110 \mathrm{kV}$ line by $120 \mathrm{~mm}^{2}$ per $1 \mathrm{~km}$ on average, adding $50 \mathrm{~km}$ of the $110 \mathrm{kV}$ line,

- increasing the cross-section of the MV line by $35 \mathrm{~mm}^{2}$ per $1 \mathrm{~km}$ on average, adding $10 \%$ of the MV line,

- increasing the cross-section of the LV line by $25 \mathrm{~mm}^{2}$ per $1 \mathrm{~km}$ on average,

- increasing the number of MV/LV stations by $10 \%$, increasing the length of LV lines by $10 \%$,

- replacing induction meters by static meters,

- replacing all MV/LV transformers produced before 1975 by modern transformers,

- replacing some of the existing transformers, with the cost of investment assumed as the cost of purchasing $10 \%$ of transformers with respect to the current number. For each newly purchased transformer, four will be replaced. The cost of replacing one transformer is estimated as 2,000 PLN.

Table 6 presents the profitability analysis of the investment in the area units. 
Table 6. Profitability of the investment in the area units.

\begin{tabular}{|c|c|c|c|c|c|c|c|c|}
\hline & OSD1 & OSD2 & OSD3 & OSD4 & OSD5 & OSD6 & OSD7 & OSD8 \\
\hline \multicolumn{9}{|c|}{$50 \mathrm{~km}$ of $110 \mathrm{kV}$ lines } \\
\hline $\operatorname{IRR}[\%]$ & 0.71 & 1.09 & 2.89 & 1.38 & 1.45 & -0.97 & 1.54 & 0.41 \\
\hline NPV $[\mathrm{m} . \mathrm{PLN}]$ & -1.4 & -1.2 & -0.5 & -1.1 & -1.1 & -2.5 & -1.0 & -1.49 \\
\hline SPBT [years] & 22.8 & 21.8 & 18.1 & 21.0 & 20.8 & 22.2 & 20.6 & 23.7 \\
\hline \multicolumn{9}{|c|}{$10 \%$ of LV lines } \\
\hline IRR $[\%]$ & 0.23 & 0.69 & 2.00 & 0.48 & 0.41 & 0.49 & -0.2 & 0.24 \\
\hline $\begin{array}{c}\text { NPV } \\
\text { [thousand PLN] }\end{array}$ & -82 & -62 & -16 & -74 & -87 & -83 & -112 & -59 \\
\hline SPBT [years] & 24.4 & 23.4 & 20.4 & 24.2 & 23.9 & 24.2 & 24.2 & 24.4 \\
\hline \multicolumn{9}{|c|}{$10 \%$ of MV lines } \\
\hline IRR [\%] & 0.67 & 0.7 & 1.33 & 1.59 & 0.94 & 1.23 & 1.52 & 0.44 \\
\hline $\mathrm{NPV}[\mathrm{m} . \mathrm{PLN}]$ & -110 & -72 & -18 & -63 & -75 & -77 & -75 & -77 \\
\hline SPBT[years] & 23.4 & 23.0 & 21.9 & 21.7 & 22.7 & 22.9 & 20.5 & 23.9 \\
\hline \multicolumn{9}{|c|}{$10 \%$ of $\mathrm{MV} / \mathrm{LV}$ stations } \\
\hline IRR [\%] & 1.16 & 0.75 & 7.74 & 1.83 & 2.58 & 1.91 & 1.43 & 1.12 \\
\hline NPV [m. PLN] & -14.8 & -11.2 & 6.2 & -9.4 & -5.8 & -10.1 & -15.7 & -9.1 \\
\hline SPBT [years] & 21.9 & 22.7 & 11.3 & 20.7 & 18.7 & 20.7 & 20.3 & 21.9 \\
\hline \multicolumn{9}{|c|}{ Replacing meters } \\
\hline IRR [\%] & -0.4 & -4.2 & -2.8 & -0.8 & -1 & -0.1 & -0.9 & -0.3 \\
\hline $\mathrm{NPV}[\mathrm{m} . \mathrm{PLN}]$ & -11 & -19 & -6 & -8 & -16 & -19 & -17 & -9 \\
\hline SPBT [lata] & 12.8 & 6.8 & 9.7 & 13.4 & 13.8 & 12.5 & 13.6 & 6.3 \\
\hline \multicolumn{9}{|c|}{ Replacing transformers } \\
\hline IRR [\%] & 3.6 & 4.25 & 8.87 & 1.67 & 4.33 & 2.8 & 2.93 & 1.91 \\
\hline NPV [m. PLN] & -1.5 & 0.6 & 0.3 & -9.4 & 0.4 & -2.3 & -2.0 & -3.2 \\
\hline SPBT [years] & 22.1 & 20.2 & 10.2 & 25.1 & 19.9 & 20.3 & 19.9 & 24.3 \\
\hline \multicolumn{9}{|c|}{ Increasing the load by $10 \%$ in $\mathrm{MV} / \mathrm{LV}$ transformers } \\
\hline IRR [\%] & -1.2 & 0.2 & -0.6 & -8.6 & -1.0 & -3.6 & -4.9 & -2.6 \\
\hline NPV [m. PLN] & -13 & -7 & -5 & -19 & -10 & -14 & -21 & -9 \\
\hline SPBT [years] & 19.2 & 17.1 & 27.4 & 18.7 & 18.4 & 19.7 & 21.5 & 19.2 \\
\hline
\end{tabular}

Replacing transformers produced before the year 1975 by modern ones is the most profitable in OSD3, with the gain of $8.87 \%$, in OSD2, with the gain of 4.25 and in OSD5, with the gain of 4.33 . In the other units it is also beneficial, with the gain about $2 \%$. In the case of replacing transformers, the magnitude of the gain depends on mean power and load coefficients in transformers produced before 1975.

Increasing the number of MV/LV transformer stations will yield the return of $7.74 \%$ in OSD3. Also in this unit, increasing the cross-section by $120 \mathrm{~mm}^{2}$ per each kilometer of the $50 \mathrm{~km}$ of the $110 \mathrm{kV}$ line will yield the return of $2.89 \%$ after 20 years. Increasing the crosssection of $10 \%$ of the MV lines by $35 \mathrm{~mm}^{2}$ in OSD5 yields a $2.5 \%$ return on investment. Replacing induction meters by static meters will not be profitable due to high cost of such a replacement and short life of the meters. Increasing the load coefficient of transformers will not yield any return either. It was assumed that for each newly purchased MV/LV transformer, four other transformers will be replaced by ones with power adequately selected with respect to load. Since the cost of purchasing a new transformer is high, such an investment will not yield a return. On the other hand, other actions that do not require investment or incur cost should be taken to ensure that the load of transformers is economically justifiable. 


\section{Concluding remarks}

The greatest percentage of energy loss is constituted by load loss in MV lines as well as loss in MV/LV transformers. Increasing the cross-section of MV lines and increasing the number of $\mathrm{MV} / \mathrm{LV}$ stations contributes the greatest reduction of energy loss. The exact level of loss reduction varies significantly from one OSD to another.

The analysis of the distribution network offered in this paper took into account only reducing losses of electric energy and the calculations were based on mean values. Therefore, even though the analysis may indicate that a given OSD on the whole will get little benefit from investment, there may be particular lines within this OSD in which increasing the cross-section may yield large energy savings.

In the LV network the greatest loss reduction will be obtained by increasing the number of MV/LV stations. The effect of adding new MV/LV stations will be the most beneficial for OSD3.

Increasing the cross-section of lines in the LV network will bring about loss reduction too, but the effect will be much smaller than that achieved by increasing the number of $\mathrm{MV} / \mathrm{LV}$ stations.

The most profitable action is replacing high-loss MV/LV transformers by low-loss ones. Due to short period of exploitation, it is not beneficial to replace induction meters by static ones.

\section{References}

1. A. Gawlak, „The Influence of Investment on Reducing Energy Losses in Distribution Networks", in Proc. 16th International Scientific Conference on Electric Power Engineering, pp. 315-319, (2015)

2. J. Sowiński, "Comparison of RAINS and Fisher's models for calculating sulphur deposition in Poland", Atmospheric Environment Vol.29, No.22, pp.3385-3389, (1995)

3. M. Kornatka, "The weighted kernel density estimation methods for analysing reliability of electricity supply" in Proc. 17th International Scientific Conference on Electric Power Engineering, pp. 2-5 (2016)

4. A. Gawlak, „Noninvestment Forms of Reducing Energy Losses in Distribution Networks" in Proc. 8th International Scientific Symposium on Electrical Power Engineering, pp. 61-64, (2015)

5. M. Kornatka and A. Gawlak, , „Comparative Analysis of Operating Conditions in Polish Medium-voltage and $110 \mathrm{kV}$ Networks" in Proc. 8th International Scientific Symposium on Electrical Power Engineering, pp. 57-60 (2015)

6. A. Gawlak, "Analysis of technical losses in the low and medium voltage power network." in Proc. 11th International Scientific Conference on Electrical Power Engineering pp. 119-123, (2010)

7. M. Kolcun, M. Kornatka, A. Gawlak and Z. Čonka, "Benchmarking the reliability of medium-voltage lines," Journal of Electrical Engineering vol. 68 (3), pp. 212-215, (2017)

8. A. Gawlak, "Technological aspects of electrical energy distribution", in Proc. $14^{\text {th }}$ International Scientific Conference Electric Power Engineering, pp.45-48, (2014)

9. J. Paska, "Ekonomika w elektroenergetyce", Oficyna Wydawnicza Politechniki Warszawskiej, (2007) 